\title{
Miradas encontradas. Sociedades y ciudadanías de España y Estados Unidos
}

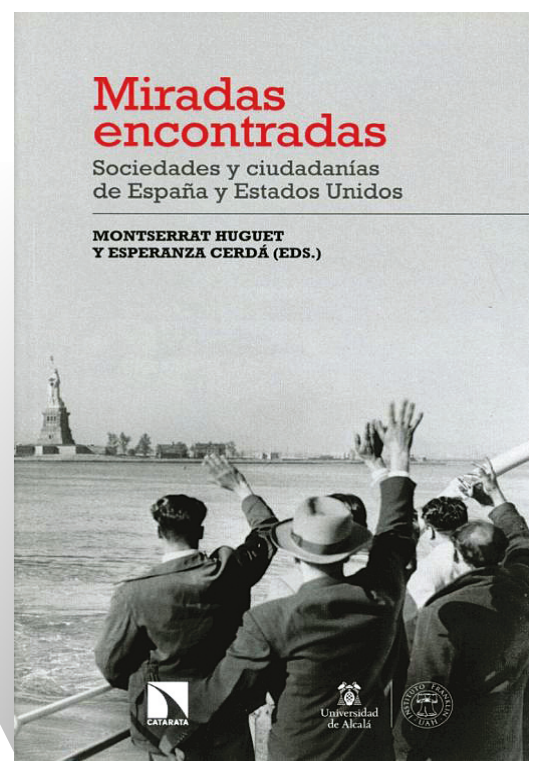

FICHA BIBLIOGRÁFICA

Montserrat Huguet, Esperanza Cerdá (Eds.): Miradas encontradas. Sociedades y ciudadanías de España y Estados Unidos, Madrid, Catarata, 2019, 301 pp., ISBN: 978-84-9097-728-6

Juan Carlos Pereira Castañares I Universidad Complutense de Madrid

HACE UNOS AÑOS, ESCRIBí UN TRABAJO sobre las características generales y los factores condicionantes de la política exterior española, en el que expresaba mi sorpresa al hacer un balance de la historiografía española sobre el tema, en el que destacaba el reducido número de especialistas y obras españolas sobre Estados Unidos, frente, por ejemplo, a los que se ocupaban de la URSS y el espacio ya postsoviético. A nadie se le escapa que el peso, la influencia y el volumen de relaciones entre ambas superpotencias eran totalmente desiguales en y para España.

Afortunadamente ese panorama ha cambiado en la última década. Instituciones como el Instituto de Investigación en Estudios Norteamericanos Benjamín Franklin de la Universidad de Alcalá, que copatrocina este libro; el Instituto Francisco de Vitoria de la Universidad Carlos III; los think tank españoles como el CIDOB, Instituto Elcano o Fundación Alternativas, así como profesores en diversas universidades españolas han contribuido a cambiar este 
panorama. Pero todas esas instituciones no hacen esta labor sin los investigadores, profesores o analistas dedicados a Estados Unidos desde perspectivas diversas. Una muestra de este nuevo y prometedor panorama es el libro que reseñamos.

Mas de 300 páginas, ocho especialistas de campos diversos, aunque mayoritariamente historiadores, autores con obras de referencia y prestigio, y en muchos casos activos organizadores de actividades diversas para potenciar el campo de las relaciones hispano-norteamericanas participan en este libro. Los ocho capítulos serán reseñados a continuación. En cada uno de ellos el lector encontrará análisis rigurosos, bien escritos, apoyados en una amplia literatura especializada y con argumentos sugerentes. A todo ello se une una amplia bibliografía en cada uno de los capítulos que es muy útil para cualquier especialista o interesado. Veamos sus aportaciones.

El primer trabajo que se presenta en esta obra colectiva es de lo más acertado y está escrito por el profesor José Luís Neila, autor de una larga bibliografía sobre Historia de las Relaciones Internacionales y con una reciente obra El destino manifiesto de una idea: Estados Unidos en el Sistema Internacional, que justifica plenamente la autoría de este artículo. En él se nos hace una presentación de los dos protagonistas de este libro, España y Estados Unidos, en un contexto temporal bien definido, 1898- años 30 del siglo XX, analizando los aspectos más relevantes no sólo de su política exterior sino de sus actores principales e incluso de la organización de su Administración Exterior. Indudablemente los dos Estados en este contexto no son comparables ni por recursos, ni por su presencia en el mundo, ni por el poder que podrían ejercer en ese periodo (estamos hablando ya de la pax americana), pero es evidente también que será uno de los momentos de mayor cercanía, aunque casi siempre desde la perspectiva del conflicto y sus consecuencias. Términos como Imperialismo, Frontera, Destino Manifiesto, Aislamiento, Neutralidad o Pacifismo, caracterizarán la política exterior de este periodo. Recogimiento, Guerra, Crisis, Neutralidad o Modernización definirán para España en sus líneas generales la acción exterior con implicaciones hacia el interior.

Partiendo ya de este contexto bien asentado, la Directora Ejecutiva del Instituto Internacional en España, Pilar Piñón, aborda con gran precisión a una de las grandes protagonistas de esta ciudadanía de la que habla el título del libro: las mujeres. Y lo hace a través de la estrecha relación que se estableció entre la Institución Libre de Enseñanza y su aliado norteamericano International Institute for Girls in Spain, fundado en Boston en 1892, con el fin de favorecer la educación de las mujeres españolas. Dos instituciones centrales, especialmente para España, que permitieron el intercambio de jóvenes universitarias de ambos países y que como reconoció María de Maeztu ofrecían a las mujeres españolas "la posibilidad de disfrutar del estímulo, inspiración e ideales que ofrece la educación y que debería ser un derecho de nacimiento para todas las mujeres". El detallado estudio ofrece un amplio análisis cuantitativo y cualitativo de esos intercambios, destacando como a pesar de las circunstancias políticas o internacionales en ambos países, este proceso coincidió con un periodo denominado Spanish Craze o "fascinación por lo español" en Estados Unidos.

Demostrando la buena coordinación de las editoras, el trabajo anterior tiene una continuidad casi sin sobresaltos con el artículo de la profesora Carmen de la Guardia, una de las pocas especialistas en temas norteamericanos en España, sobre el exilio de muchas mujeres republicanas en Estados Unidos. Su interesante estudio parte de un planteamiento, 
en mi opinión central: no sólo fueron los hombres -intelectuales o políticos- los grandes protagonistas del exilio después de la fratricida guerra española, tantas veces estudiados, sino también el importante papel jugado por muchas mujeres que se desplazaron a Estados Unidos desde diferentes posiciones. Como intelectuales, como "conectoras" creando y manteniendo a través del contacto epistolar las redes familiares, como profesionales o sencillamente como representantes de ese "Grupo de Modernas" vinculadas a partidos de izquierda y movimientos feministas. Un plantel que es analizado con detalle minucioso por Carmen de la Guardia, gracias al cual se impulsó el hispanismo y se fortaleció un grupo de españoles obligados, de nuevo, a abandonar su país por razones políticas. De todos los centros destacados, el Spanish School de Middlebury Collegue fue el más importante para esta autora y otros colaboradores en este libro.

De nuevo, la profesora Carolina Rodríguez-López aborda el tema de exilio en Estados Unidos desde una perspectiva novedosa metodológicamente, la historia cultural de las emociones. Su planteamiento nos describe, como afirma, la "cartografía humana y emocional" del exilio español de muchos profesores e intelectuales españoles desde 1936 a Estados Unidos. La situación política, bélica y represora que se impuso en España desde el inicio de la guerra, obligó a muchos profesores españoles a decidirse por el exilio y entre los destinos preferidos por muchos de ellos fue el de Estados Unidos, en donde españoles como Federico de Onís, Angel del Río o Rafael Lorente de No, habían abierto camino mucho antes gracias a las becas recibidas en los años de la República. Poco a poco el número de estos exiliados fue creciendo -se analiza de forma pormenorizada este trasvase de "intelectualidad" - que incluían profesores de distintas ramas y especialidades, algunos de los cuales llegaron a ocupar cátedras y puestos de alta responsabilidad en las siguientes décadas. Por último, para aplicar su marco de análisis teórico-metodológico la autora se ocupará de tres personajes centrales: Pedro Salinas, Fernando de los Ríos y Américo Castro. Como bien dice Carolina Rodríguez-López, "Los exiliados no eran personas distintas en esencia a las que eran cuando iniciaron el exilio, pero si acabaron siendo personas nuevas, formadas por las nuevas circunstancias americanas".

Una de las editoras, la profesora Montserrat Huguet, aborda en su capítulo el tema de los imaginarios en este caso desde Estados Unidos hacia España en el siglo XX. La profesora Huguet lleva trabajando en los últimos años de forma intensa sobre Estados Unidos y las relaciones con España desde perspectivas muy novedosas y además en un amplio periodo cronológico. En su capítulo, muy sugerente, se hace un repaso del conjunto de imágenes y percepciones que se ha tenido en Estados Unidos de España desde principios del siglo XX hasta casi su último tercio. A través de los escritos de periodistas, diplomáticos, intelectuales o destacados políticos se van reflejando esas percepciones que son, palabras de la autora, "fluctuantes, evasivas y en bastantes ocasiones desfavorables". Leyendo su artículo recordaba lo que mis estudiantes norteamericanos, años tras años, me comentan en sus trabajos sobre la imagen de España antes y después de su estancia. Un desconocimiento generalizado, una centralidad en la Guerra Civil, la persistencia de ideas cercanas a la "Leyenda Negra" y un país de buen vivir en donde la siesta y la fiesta van unidas a la personalidad del español. Resulta esclarecedor como a pesar de los años y los cambios políticos y económicos españoles, el elemento común en esas percepciones desde el otro lado del 
Atlántico sea el de la "excepcionalidad", representada por la autodestrucción y la incapacidad para normalizar la historia española dentro de un contexto global.

A continuación Lorenzo Delgado, investigador reconocido por su amplia bibliografía y especialmente por su dedicación en proyectos y libros a las relaciones hispano-norteamericanas a través de la diplomacia pública norteamericana y las transferencias culturales, educativas y culturales, aborda en su trabajo una de las iniciativas más relevantes en el ámbito de su estudio: el Programa Fulbright. Se creó al final de la II Guerra Mundial para impulsar el conocimiento de los pueblos y evitar un nuevo conflicto, en el contexto del internacionalismo cultural de entreguerras y del nuevo papel mundial que iba a jugar Estados Unidos en el mundo. Desde 1946 ha ido evolucionando de forma desigual, como bien analiza el autor, en función de los presupuestos, los intereses norteamericanos y la coyuntura internacional. En España se establece en 1958 y hasta hoy más de 5.500 españoles se han desplazado a universidades y centros de investigación norteamericanos y más de 3.200 norteamericanos han pasado estancias en centros y ciudades distintas de España. Su riguroso análisis demuestra los diferentes intereses, lugares de trabajo y actividades desde ambos lados, pero lo que es indudable es la provechosa experiencia -personal y profesional- para esos miles de españoles que han disfrutado de ese programa y la importancia que para las relaciones culturales ha tenido, y tiene, la iniciativa creada por el senador J. William Fulbright.

El sociólogo y profesor Rubén Díez, demuestra en su artículo la solidez de sus investigaciones a través de un estudio comparado de movimientos sociales en los años sesenta del siglo pasado, considerando a estos como vehículos de transmisión y difusión de ideas, valores y creencias tanto en el espacio como en el tiempo. Es original su planteamiento e interesante su discurso narrativo a través de las tres jóvenes estudiantes norteamericanas - Roberta, Karen y Carol- que llegan a España en un momento en el que el movimiento de oposición del franquismo está creciendo- finales de los años sesenta- y conectan con universitarios españoles en clara oposición al régimen. De esta manera España - de forma limitada, claro- conecta con esa ola de protestas contra la intervención norteamericana en Vietnam y los gobiernos y el poder. Su atractivo trabajo no olvida tampoco la perspectiva sociológica comparada a través de las llamadas dinámicas transnacionales, el papel de las generaciones jóvenes en el activismo actual, los procesos de inversión cognitiva y emocional y de construcción de identidades nacionales, la critica a las estructuras jerárquicas y autoritarias y la tendencia a las acciones autónomas de sectores sociales fuera de las organizaciones políticas.

Por último, el profesor Misael Arturo López Zapico, otro de los principales estudiosos e investigadores de Estados Unidos y sus relaciones con España, nos presenta un artículo sobre una de sus líneas de investigación más relevantes: el antiamericanismo en España. Tras exponer las interpretaciones que sobre este concepto parecen existir en la literatura especializada, apoya la tesis de que su uso se limite a aquellas situaciones en las que la hostilidad a Estados Unidos supere a la que puede sentirse hacia otros países y que a su vez ese "odio" se dirija a la nación en su conjunto y no a unos aspectos concretos. Acudiendo a imágenes simbólicas en España de las oscilaciones del anti y el pro americanismo -Zapatero no levantándose ante el paso de la bandera norteamericana en 2003 y Aznar en la Cumbre de las Azores-, hace un análisis muy riguroso y acertado en mi opinión de la actitud ante Estados Unidos durante el segundo mandato de Aznar y el periodo presidencial de Rodríguez Zapatero. Su discurso se 
completa con un buen estado de la cuestión, llegando a la conclusión de que el antiamericanismo español no es algo ni excepcional ni tan profundo como podría creerse y se mantiene al nivel de otros países de nuestro entorno e incluso más aún, esa actitud de una parte de la sociedad - en muchos casos identificada con la izquierda y los jóvenes- en muchas ocasiones se centra más en el rechazo a los presidentes y su círculo de poder que a la propia sociedad y el Estado norteamericano.

Lo dicho. Gran aportación multicoral y rigurosa, que viene a demostrar el resurgimiento de un ámbito de estudio en España como es el de las relaciones entre hispano-norteamericana, desde perspectivas nuevas y no sólo diplomáticas, que hoy siguen siendo una de las más importantes para nuestro país. Y ello a pesar de Donald Trump! 